\title{
Where Words Trap the Mind: The Bewitchment of Psychotherapy
}

\author{
Chin $\mathrm{Li}^{1}$ \\ Formerly Consultant Clinical Psychologist
}

\begin{abstract}
When psychotherapists reify the concepts they are using to describe human experiences, both therapist and patient are likely to end up with befuddled thinking, and become unable to grasp the lived experience of the emotional turmoil the patient is struggling with. In this context, proper use of language is of vital importance, and the first task of the psychotherapist is to think clearly about what she is doing in the therapy room and the words she uses. This essay attempts to clarify some of these issues, and to discuss their relevance to the practice of psychotherapy.
\end{abstract}

\section{Introduction}

Some fifty years ago, Jean-Paul Sartre published a tape transcript of a "psychoanalytic dialogue" he obtained from a patient. ${ }^{2}$ The dialogue was recorded secretly by the patient during an analytic session. Once the patient had produced the tape-recorder from his pocket, the analyst refused to say anything other than demanding the immediate withdrawal of the patient from the consulting room. It transpired that the patient had taken a long time to consider such an action. He wanted the analyst to explain what he had done to him over the years. He also wanted to know what the therapeutic cure was supposed to be. Most importantly, he wanted to have this discussion face to face without the couch, and he wanted an audio record of what the analyst said.

The transcript clearly conveys a sense of panic the analyst feels in this unexpected situation, where the patient has suddenly taken on an active role, upsetting the power balance between the two participants. Besides demanding an explanation of the "science" of psychoanalysis, the patient challenges the dubious nature of his analyst's previous pronouncements (interpretations) by using the latter's concepts such as castration fear or father-complex to explain the analyst's agitated behaviour in the present situation. The result is a comic but also thought-provoking record of the exchanges between an expert and a person labelled as a patient, in an "analytic hour" that has undergone a most unusual mutation.

Sartre has commented that the crucial point about the "dialogue" is that the hitherto passive "patient" - the object of the analysis - has become an active agent, that is, a subject. The idea of subject is fundamental to Sartre's existentialist philosophy. In

${ }^{1}$ Correspondence concerning this article should be addressed to Dr. Chin Li, Email: Chinkeung.Li@gmx.com

2 Originally the "Psychoanalytic Dialogue" was published in April 1969 in the journal Les Temps Modernes; the article was later reprinted in Sartre, J-P (1974). Between Existentialism and Marxism.

Language and Psychoanalysis, 2018, 7 (1), 84-105.

http://dx.doi.org/10.7565/landp.v7i1.1584 
acting as a subject, the patient demands to be treated as autonomous. To turn the table on his challenger, the psychoanalyst declares the patient dangerous and out of touch with reality. In doing so, he is trying to wrest back control through labelling the patient with words that could condemn the latter to psychiatric incarceration. Words uttered by professionals carry the authority of institutional sanction, reflecting the power imbalance between experts and lay-people.

Some years ago, a collection of papers (Casement, 2004) was published with the provocative title Who Owns Psychoanalysis? It contains material about the conflicts between different factions within psychoanalysis. But what interests me is more the fact that "ownership" has arisen as an issue in the first place. The idea of ownership is not just to do with possession of physical resources and means of production in the material world; it is, more importantly, to do with control of the superstructure of a society, of which language and meanings are vital constituents. Ownership, in this regard, embodies the right to decide what orthodoxy is and what is judged to be heresy. It also controls the delineation of who is "in" and who is "out", thus defining "us" versus "them". In exercising such power, those who owns the right to produce meanings ensure that truth, or Truth, is established in accordance with their view.

Freud no doubt saw himself as the sole originator, and hence owner, of psychoanalysis; and to that extent, he believed he was the guarantor of the purity of psychoanalytic knowledge. His demand that his disciples should guard the "pure gold of psychoanalysis" was not dissimilar to Saint Paul's instruction to Christians to "guard the Gospel". The phenomenon of claiming authority through lineage ("I was analysed by her, who was analysed by him, who was analysed by Freud.") is similar to the apostolic genealogy linking the current Pope all the way back to Saint Peter, who was supposedly enthroned by Christ as the rock (the head) of the Catholic Church. A fundamental conflict between different sects of psychoanalysts revolves round the question of who is truly faithful to the Founder, or who has definitively preserved the gem of psychoanalytic truths. In this regard, it is not inappropriate to compare the whole edifice of psychoanalysis to a religious faith. ${ }^{3}$

In this connection, it is interesting to note that Adam Phillips (2007), the general editor of the New Penguin Freud series, wanted to avoid "psychoanalytic politics" when organising the new translation of Freud's work. He wanted as many nonanalysts as possible to do the translation so as to allow different voices to emerge. $\mathrm{He}$ believed that to promote a single-translator Standard Edition would lead to dogmatic canon formation harmful to psychoanalysis, particularly if only analysts were involved or if the project was under the control of psychoanalytic institutions.

According to Adam Phillips (2014), Freud began his exploration of the human psyche with uncertainty but ended up becoming overly certain. In my view, dogmatic certainty gives a false sense of power which stifles creativity and new discoveries, whereas genuine openness extends the horizon of understanding. Treating all theories, including psychoanalysis, as provisional may prove to be a fruitful way of thinking about psychotherapy.

${ }^{3}$ For a classic critique of psychoanalysis as (quasi-)religion, see Gellner (1985).

Language and Psychoanalysis, 2018, 7 (1), 84-105. 


\section{Putting "Neuro" into Psychoanalysis?}

While Freud's work is undoubtedly instrumental in making the unconscious a dominant concept in modern culture, this concept has been grappled with by many thinkers long before Freud (see Ellenberger, 1970). Thus it is important that the development of Freud's ideas be seen in the context of the intellectual history of Europe, particularly in relation to nineteenth century German Idealism in philosophy (e.g., Hegel or Schelling; see Fenichel, 2015). As Ffytche (2011) has cogently argued, the question is not whether Freud inherited the unconscious from earlier writers, but which version of it did he inherit. It would be fair to say that the emergence of the notion of the unconscious in Freud's work (and related concepts like repression or the Oedipus Complex) was made possible by the cultural milieu of the day. Thus it is not helpful to talk about Freud "discovering" the unconscious (or the Oedipus Complex) as similar to Joseph Priestley discovering oxygen in the field of chemistry.

A more fundamental question to "what is the unconscious" is no doubt what is consciousness? This is a conundrum that philosophers have been (unsuccessfully, I feel) struggling with throughout history. In contemporary psychoanalysis, there is an attempt to bring the neurosciences to bear on this question (Kaplan-Solms \& Solms, 2000; Levin, 2003; Oppenheim, 2005; Solms, 2013; Solms \& Turnbull 2002).

The thrust of Mark Solms' work is to bolster the credibility of Freud's ideas by appealing to the findings of neurosciences (hence neuropsychoanalysis). Solms believes that his work is a continuation of Freud's 1895 "Project for a Scientific Psychology", with the aim of establishing the neuroscientific basis for psychoanalysis. In working towards this goal, Solms also tackles the question of how consciousness has arisen.

While Solms does acknowledge that the "hard problem" of consciousness is far from resolved (how consciousness emerges from matter), he is adamant that the "easy problem" of consciousness (how neuro-chemical processes correlate with cognitive functions) has already been subject to rigorous research resulting in a lot of important findings. His own solution to the "hard problem" is "dual-aspect monism", which suggests that:

we are made of only one type of stuff but ... this stuff is perceived in two different ways... in our essence we are neither mental nor physical beings... the brain is made of stuff that appears "physical" when viewed from the outside (as an object) and "mental" when viewed from the inside (as a subject). When I perceive myself externally (in the mirror, for example) and internally (through introspection), I am perceiving the same thing in two different ways (as a body and a mind, respectively). (Solms \& Turnbull, 2002, p. 56, original emphasis)

Essentially, Solms is saying that the distinction between mind and brain is just an artefact of perception. He then goes on to say: 
The mind itself is unconscious, but we perceive it consciously by looking inwards.

It is this capacity for "looking inwards" (for introspection or self-awareness) that is the most essential property of a mind. (Solms \& Turnbull, 2002, pp. 76-77, emphasis added)

What Solms has said here begs a number of questions. First, the phrase "the mind itself" implies there is a boundary to the mind which could be distinguished from what is not mind; secondly, the "we" is deemed to be separate from the "mind" as this "we" could "perceive" the mind, i.e., "we" being the subject and "mind" the object and "looking inwards" being the action of the "we" on the "mind"; and thirdly, he said "looking inwards" is an important capacity of the "mind", which suggests "we" (the subject doing the looking) and the "mind" (that which is being looked at) are one and the same, which is confusing. Moreover, the word "inwards" is difficult to explicate, where is "inwards" and how is looking inwards achieved?

My view is that the mind is inseparable from a person's immediate phenomenal experience, and is not some thing transparent to itself. To analyse what it means by "the mind looking into itself" will only lead to an infinite regress, i.e., is the mind analysing what it means by the mind looking into the mind? This is pure confusion.

Solms' distinction between perceiving himself externally and perceiving himself internally is equally perplexing. Seeing one's image in a mirror cannot be equated with seeing one's self because the mirror-image is not a self, but the optical effect of light on a reflective surface. Also, this seeing is not external in the literal sense - this seeing oneself in the mirror is always an internal process involving the visual cortex, the prefrontal lobe, and the complex function of self-recognition. To say this "external" perception and perceiving oneself through introspection are two different ways of perceiving "the same thing" (where and what is this "thing"?) has set up a dubious distinction, to say the least.

Solms" "monism" implies that matter is the only stuff there is, which means "we", the brain, and the mind are all made of the same stuff. The unanswered question is how does this one and only stuff (matter) separate into brain and mind, and is this "we" the brain or the mind? To me, dual-aspect monism has not achieved its goal of resolving the "hard problem" of consciousness.

In relation to psychoanalysis, Solms (2013) argues that the id is associated with the brainstem and subcortical structures regulating affective states, while the ego is associated with the prefrontal cortex and executive functions. The brain structures involved in interoceptive perceptions and affect regulation are seen as the neurological basis for Freud's pleasure principle, and hence locating id in these structures is deemed appropriate. As consciousness, in Solms' view, is generated by the brainstem, he believes consciousness is not to do with perception and cognition (functions of the frontal lobe, where the ego is located) but with affect and instinct, that is, the id. As consciousness is not generated in the cortex, he concludes that the ego is unconscious while the id is conscious, thus turning Freud's idea on its head! 
The logic of Solms' argument is as follows: id is defined (not independently verified) as to do with affect (the pleasure principle), and as the brainstem is correlated with affect and also with consciousness, so id must be localised in the brainstem and is therefore "conscious". But this is merely giving the label "id" to the brainstem processes without adding anything. Thus Solms' reasoning is circular or tautological.

Solms further suggests that the therapeutic effectiveness of psychoanalysis is through changing the brain by "rekindling" critical periods of frontal lobe development artificially via the regressive transference relationship, and through extending the functional sphere of influence of the prefrontal lobes via language and internalisation, thereby strengthening the ego (Solms \& Turnbull, 2002, pp. 287-289). This is an unsubstantiated hypothesis that is struggling to put the prefix "neuro" to "psychoanalysis" - a rather futile attempt.

In all of this, Solms uses the word "consciousness" in a confused way. The assertion that consciousness is generated solely by the brainstem does not distinguish wakefulness from either phenomenal consciousness or consciousness of the self. Certainly if the brainstem is damaged, an individual person would lose consciousness/wakefulness; but is a functioning brainstem, without the prefrontal cortex (and other brain structures), enough to ensure the experience of phenomenal consciousness or personal self-consciousness? Consciousness depends on the brainstem but is not identical with it.

In the concluding chapter in The Self in Neuroscience and Psychiatry, Kircher and David (2003) have outlined the central qualities of phenomenal consciousness at the core of selfhood: sense of temporal continuity/consistency, sense of agency, and sense of distinction from the environment. There is no ontological identity between phenomenal consciousness (which cannot be localised in the neurological architecture) and brain states. Perhaps the search for the neurological location of the ego or the id is an impossible enterprise. While acknowledging Freud's contribution to human understanding, the Chicago philosopher and analyst Jonathan Lear (2005) has pointed out that Freud's belief in the possibility of explaining the mind in biological terms is misguided.

\section{Whence and Wherefore Oedipus}

Language is the human phenomenon par excellence, and it constitutes a tool for the exercise of power in various ways. Not only in the world of psychotherapy, but in most areas of life - politics, the law, even the home behind closed doors. Whichever faction a psychoanalyst belongs to, the power she wields over her patient is largely to do with her ownership (and deployment) of a special language that renders the latter either clueless about what is going on or incapable of assuming the role of an independent subject. In fashioning a mechanistic language they believe represent the truth about all human beings, many analysts, including Freud, have committed a category error, which has hampered the healthy development of psychotherapy and ensnared generations of practitioners. This error is the reification of often ad hoc or context-dependent concepts into objects with thing-like properties, thus bestowing upon these concepts an ontological status they do not possess. 
One example of a category error is the statement "cortex without a brainstem can never be conscious" (Solms, 2013 p. 12). "Cortex" is an entity in the physical world whereas "conscious" is a description of a subjective phenomenon in the experiential world. We can (and do) say "I am conscious" but not (as Solms does) "my brainstem is conscious" or "my memory is conscious". To mix the two up is a classic category error which leads to dubious theorising.

Another example is the Oedipal Complex. Instead of being treated as a metaphor for the purpose of giving meaning to a particular person's experience (originally Freud's own), it has, through a process of theory building, become something universal, to be discovered through analysis. Similarly, "repression" has become an occurrence in the mind, with objective existence and power to control a person's life, something that can only be unearthed through psychoanalysis. Thus, analysis is not understood as a tentative, and often erroneous, groping towards a hermeneutical grasp of what has happened or is happening between individuals, but as a scientific procedure that uncovers the causes and mechanisms of neurosis.

Like many myths in antiquity, there are many variants of the Greek myth Oedipus Rex, but Freud took the one that conformed to his idea of the incestuous triangle in order to create a theory of childhood fantasy being the cause of neurosis. In other variants, the exile of Oedipus is the focus, not incest, parricide, or Oedipus's selfmutilation. The theme of wandering, of alienation, of suffering, of the difficulties of home-coming, is prominent in Greek tragedies, of which Oedipus is just one example. Another Greek epic, Odyssey, also has wandering at its heart - Odysseus' heroic attempt to return to Ithaca, his home. If wandering and alienation were given centrality in the human drama of neurosis (instead of parricide and incest), the history of psychoanalysis might have turned out differently.

The use of Greek myths in literary or philosophical discussions has a long history before Freud, and commentaries on works like Oedipus or Antigone often focused on ethical self-consciousness and responsibility (e.g., Hegel). Because of its plot involving incest and parricide, Oedipus was suppressed in England for a long time, but there was already strong fascination with it well before Freud coined the term "Oedipus Complex". As Buchanan (2010, p. 4) said, "[i]t may nevertheless seem a large leap from uncovering this suppressed classical hero to believing that his image held the secret of all of human nature". Buchanan has argued that Oedipus is at the centre of humanist discourse as a symbol of human self-awareness and a reflection of the limits of rationality. He suggests there was a nineteenth century philosophical strand that saw this myth as representing a traumatic but necessary transition from animistic, matriarchal nature-worship and superstition to enlightened patriarchal humanism. Thus Freud's interpretation of Oedipus Rex is not the only viable one.

After Freud, there have been many writers who tried to interpret Oedipus from perspectives different from psychoanalysis. Perhaps the most well-known is AntiOedipus by Gilles Deleuze and Felix Guattari, who have mounted a sustained critique of Freud's totalising dogma of the Oedipus Complex. Deleuze and Guattari (1983)

4 Unless the reader is a French philosophy expert, otherwise Deleuze and Guattari (1983) would not be easy to follow. It is a text full of anti-individualist, anti-ego, anarchist, and revolutionary polemics; nevertheless, it has been praised Language and Psychoanalysis, 2018, 7 (1), 84-105. 
believe that "oedipalisation" is a tool for oppression, and they argue that not only is Freud not radical enough, in fact psychoanalysis is very much part of the establishment. They suggest the "great discovery of psychoanalysis", i.e., the discovery of "the production of the unconscious", has been neutralized by the postulation of the Oedipus Complex (the "daddy-mommy-me" myth) which has introduced idealism into psychoanalysis. In their view, Freud has neglected the importance of Marx's materialist philosophy. They suggest that Freud's dislike of, and inability to work with, psychotic patients is to do with the latter not developing transference with the analyst and not capable of grasping Oedipal interpretations. Deleuze and Guattari describe such patients as resisting being oedipalised. Instead of psychoanalysis, they believe schizoanalysis is the way forward.

Whether we agree with Deleuze and Guattari or not, it is no doubting that right from the beginning, questions about the unconscious (and related issues such as the Oedipus Complex or repressed sexuality) have occupied the thinking public in more ways than one, and have led to disagreements, debates and controversies.

\section{Reification of Experience}

Language is fundamentally metaphorical - more often than not, words are used to achieve a purpose rather than pointing to things. Wittgenstein famously said "the meaning of a word is its use in the language". A dictionary does not exhaust the meanings of words: usage changes and evolves, and no one is bound by the normative definition of words. Even in the area of the law, whether in day-to-day practice or legislative processes, the meaning of words is often subject to fierce debate resulting in unresolved disagreement.

Thus, words often serve as gateways to meanings in psychotherapy, not labels for concrete objects. While I am not denying that words, e.g., "table", may point to physical things, my contention is, for psychologists and psychotherapists, it is the metaphorical quality of language and the connotative complexity of words that we should attend to.

In an important, but neglected, paper published half a century ago, the psychoanalyst James Home has elaborated a cogent critique of the kind of mechanistic psychoanalysis which delights in obscure vocabularies and meaningless assertions. Home (1966) argues that psychoanalysis belongs to the realm of humanities rather than the world of science. The confusion between "causes" (appropriate for physical sciences) and "reasons" (required for understanding suffering and psychotherapy) is, Home suggests, what led Freud into the trap of reification. Home said "a meaning is not the product of causes but the creation of a subject" (1966, p. 43), and "[t]o define mind as the meaning of behaviour is to remind ourselves that mind is not a thing and

by Michel Foucault as a masterpiece of anti-fascism.

${ }^{5}$ While this quote (Wittgenstein, 1958, Para 43) should be read in the context of Wittgenstein's detailed and complex analysis of "language-game", it is relevant to the discussion here of the metaphorical as well as connotative function of words in the production of meaning in therapy. The importance of Wittgenstein's work to psychoanalysis and psychotherapy is cogently argued in Heaton (2010).

Language and Psychoanalysis, 2018, 7 (1), 84-105.

http://dx.doi.org/10.7565/landp.v7i1.1584 
cannot therefore be analysed as such. Mind as meaning is a quality inseparable from life, as is the concept of a subject" (p. 46). Furthermore, mind is not accessible to introspection, because "to introspection it [the mind] is infinitely recessive. We can never observe the 'I' that observes" (p. 47).

Mind, or "self" can only be known to the subject through her indwelling of an embodied existence in an inseparable relationship to the physical and social world. This is the subject's experience of phenomenal consciousness, not open to investigation with the logic and methods of physical science.

Writing a patient's official "story" is a manifestation of institutional control that the professional has over the patient. It is the expert defining the "self" of the patient. In such writings, reification is prevalent. It is common for psychiatrists to write clinical reports with statements like this: "mental state examination revealed a thin lady with..." - the implication of this way of talking is that assessing a person's emotional experience is akin to physical examination in physical medicine where findings such as "physical examination revealed a tender lump in the upper right abdominal area..." are important. The reification of the person (and her experience) into a thing is so blatant in such clinical reports it is hard to understand why so many psychiatrists remain unaware of what they are doing.

There are analysts who acknowledge the distinction between the concept of meaning and that of cause, but still stick to a causal model of psychological distress, arguing that the intertwining of meaning and cause is what characterises the human subject. ${ }^{6}$ But how such intertwining is possible is often left unexplained, leaving unresolved the age-old dualist problem of how non-material aspects of experience (meaning, reason, belief) could produce causal effects in the material world (observable behaviour, physical mechanisms, etc).

The implication of Home's argument for psychoanalysis is profound. It is a different language, and a different practice, that has to be developed, not one modelled on "mechanistic medicine" ("mental state examination revealed a thin lady with..."). Although coming from a different perspective, the British clinical psychologist David Smail has written much about how both psychoanalytic and cognitive-behaviour psychotherapies have failed to do justice to human experience:

$[\mathrm{P}]$ sychotherapy takes place in an ideological context of which it itself forms a part... The kind of psychotherapy which is subversive of ideology in the sense used here reveals a world in which we live and which gives us pain. It also gives back meanings to our feelings: for example, it may reveal depression not as the undesirable state of a disordered mechanism, but as the inevitable emotional experience of someone whose practised way of doing things no longer works, and

\footnotetext{
6 This is what the analyst David Bell (2010) has suggested. He asserts that his model addresses the meaning of a symptom, and also displays its causal structure and causal history.

Language and Psychoanalysis, 2018, 7 (1), 84-105.

http://dx.doi.org/10.7565/landp.v7i1.1584
} 
as essential emotional accompaniment of the difficulty of learning to do things differently. Psychotherapy certainly does not cure anything... and of itself probably doesn't change anything very radically; what it can do is offer to support a subjective view of an actual world which patients may then (but also may not) want and be able to influence in some way. (Smail, 1987, pp. 398-401) ${ }^{7}$

One way the psychoanalyst exercises power over her patient is to monopolise the interpretation of the latter's problem: if the patient accepts an interpretation, she acknowledges the analyst is in possession of the truth; if she rejects the interpretation, the analyst can (and often does) label her as showing resistance, a symptom of her neurosis. Thus the truth about the patient is always in the hands of the analyst. While some analysts (including Freud himself) are not unaware of this criticism, in practice, such power monopoly is difficult to change.

In relation to this, Lear (2005) has tried to defend psychoanalysis thus: "philosophically speaking, the question is not whether some analysts are bullies. Rather, the question is, 'When psychoanalysis is practiced well, is there even so a tendency towards bullying?"' (p. 21). But this is not a valid defence because (1) who decides whether this or that analyst is "practising well", and (2) bullying of patients, especially by Freud, does matter as this leads to inaccurate information (or "evidence") being accrued for the formulation of (questionable) theories.

Reification happens not only in psychoanalysis but in most forms of psychological therapy. The central concept of the many variants of cognitive-behaviour therapy (CBT), "negative automatic thoughts" (NATs), provides another example of how experience (in this case, thinking) is turned into things. Many practitioners talk about NATs as if they are entities in the head, and therapy is, simplistically, a matter of replacing these disorder-causing thoughts with positive or adaptive ones. The mechanical method of getting the patient to write down, repeatedly, positive statements (e.g., "I am not a failure") on a piece of paper ("thought record") is deemed the way to ensure therapy success. If we stop and ask, Where do thoughts reside?, we would quickly realise that the talk of NATs (or "positive thoughts") may not be a meaningful way to describe, let alone understand, human experience. But so often this is blithely ignored.

Perhaps it would not be presumptuous of me to extend Wittgenstein's dictum and say "the meaning of an experience is in its living". The crux of the matter is, meaning cannot be captured, framed or pinned down once and for all. It might be more fruitful to think of meaning as unstable, in flux, emergent. People who are totally committed to one particular view, who believe they possess certainty - people with God on their side - find it impossible to see the world, in all its messiness, clearly.

7 The late David Smail was a trenchant critic of capitalism, analysing how it underlies human misery and psychological problems. He has produced a large body of work which provides a rigorous critique of psychotherapy.

Language and Psychoanalysis, 2018, 7 (1), 84-105. 


\section{Living in the Present}

When therapists turn experiences into objects, they often talk in terms of "the past" as if the latter has an independent existence, in which all sorts of things could be found, particularly "complexes" underlying psychological symptoms.

My contention is the past is not a place; it does not exist in the ontological sense. The concept of the past, the present and the future constitutes our way of talking about experiences. We do not go back to the past as such, nor could we stay in the past. This is a metaphorical way of speaking for particular purposes of communication.

Phenomenologically, we always, and can only, experience the present, and can never escape from it. Even when we feel we are in the past, we do so in the present. However, it is important to understand that the present is not a fixed point in time, as experiencing is always a phenomenon in motion, so to speak. There is no stopping at a particular present. The future is not a place either - it is our way of imagining (or anticipating) what might happen next (or the day after). The future will inevitably become the present, in the sense that whatever we have imagined does (or does not, as the case may be) turn out the way we imagine, and we experience that in the present. The felt continuity of past-present-future is how we experience our relationship to the space-time structure of the world, in which we continue to act in accordance with our personal circumstances and the cultural milieu we inhabit.

This way of understanding the past does not deny the experience of memories, but it does suggest that memories are not things. It is more helpful to talk in terms of remembering, an act of thinking in relation to what has happened. While there are neurophysiological correlates to the act of remembering, these correlates are not fixed entities in the brain, and they are not identical to what we remember. We can never point to a memory on a brain scan. Memories change as contexts vary in which the act of remembering is undertaken.

Thus, when a psychotherapist helps a patient "recover" a crucial memory, it is not a matter of rummaging in the bottom of a drawer "in the mind" to retrieve an object, but an act of jointly creating an experience of the patient thinking, in the present, of what has happened in the past. As such, it is of paramount importance that the context of remembering, not only the patient's current life but also the patient's relationship with the therapist, be taken into account when trying to understand whatever the patient has managed to remember. Interpretation is not a technique for discovering some thing from the past but a way of pointing to possibilities of meaning.

While many psychoanalysts understand that the past is never fixed, but a creation in the present and a realm of experience full of vicissitudes, they may still see the recovery of the patient's past as a major aim of therapy (as if it is already in the mind waiting to be found), and believe only they have the knowledge and authority to ascertain whether the "past" thus unearthed is the real past or not.

\section{The Ego, the Mind and the Soul}

Psychoanalysis has evolved significantly since the time of Freud. However, the trap of reification continues to affect many, particularly in theoretical writings, even if not 
in therapy work. For example, while acknowledging the limitation of Freud's mechanistic models, some analysts still lapse into talking about the id, the ego or the superego as entities:

The id is entirely unconscious. Its contents can be considered to be equivalent to the unconscious of Freud's earlier topographical model. Its existence is inferred from derivatives such as dreams or slips of the tongue. The energy of the id is derived between two types of instincts: the life and the death instincts. (Lemma, 2003, p. 20; emphasis added $)^{8}$

When Freud formulated his ideas of the structure of the psyche, he used the common German words "it" (es), "I" (ich) and "over-I" (über-ich) to describe the three aspects of mind: the irrational, the rational and the moralistic-punitive. Freud conceptualised these forms of mental functioning as concrete mechanisms, even though he chose to use personal pronouns to label them. Perhaps the early English translators wanted to use words which looked scientific or specialist, rather than pronouns, in order to give psychoanalysis a more respectable sheen. Unfortunately, the translation of the German words into "id", "ego" and "superego" has further reified the formulation, making it much easier for the pronouns to acquire thing-like properties, to such an extent that many psychoanalysts (and other people) talk about the id (or the ego or superego) as if it has an existence independent of the actions of a human person, with its own "contents", "energy", etc. ${ }^{9}$

If, instead of "ego", we stick to "I" (but not as Freud did - he used the phrase "the I" [das Ich], which is reifying), we would no doubt think in terms of agency or subjectivity: "I" being the grammatical subject, the first person of language use, the source of actions, the creator of meaning. Unlike the connotation of the word "ego", "I" does not reside "inside" a person's "mind". "I" is the active person herself. I am struggling with the experience of conflicts - conflicts do not happen in a place called my "mind". When I said my mind is beset with conflicts, I am talking metaphorically, not referring to an internal place.

Another example of the problem of translation, as McGrath (2011) has pointed out, is the translation of the German word Trieb into English as "instinct" instead of the more accurate "drive", thus concealing the continuity of Freud's metapsychology with German idealist philosophy (such as the work of Schelling), where Trieb is of central importance. This concern has been expressed by Jean Laplanche - that collapsing "drive" (Trieb) and instinct (Instinkt) into one concept has made psychoanalysis vulnerable to biological reductionism. The "soul" was another key idea in idealist philosophy, but its appearance in Freud's work (die Seele in German) has been

8 This quote is from the psychoanalyst Alessandra Lemma, who has discussed Freud's concept of id as process but still lapses into a way of talking that reifies the id-process into an entity.

${ }^{9}$ Authors such as Sander Gilman and Bruno Bettelheim have expressed the view that the translation of Ich and Es into English as "ego" and "id" is a barrier to a proper understanding of psychoanalysis.

Language and Psychoanalysis, 2018, 7 (1), 84-105.

http://dx.doi.org/10.7565/landp.v7i1.1584 
rendered as "mind" in Strachey's Standard Edition, probably to avoid the impression of being "unscientific".

There are of course practitioners in the psychoanalytic tradition who are not afraid of using notions such as the soul. The most notable is Carl Jung, who broke away from Freud and established a separate therapeutic tradition, analytical psychology. One contemporary Jungian, Wolfgang Giegerich, has become influential in the Jungian world. ${ }^{10}$ Here is Giegerich in his own words:

As the human being is dethroned from the central place around which psychological life allegedly has to revolve, the psyche can finally in truth be recognized as what Jung tried to see it: as objective or autonomous psyche, or as I would prefer to say, as the logical life of the soul, a life that is its own (even though it lives through us and needs us to give expression to it). (Giegerich, 1996, p. 24)

It is a naïve and narcissistic mistake to take oneself so seriously as to confuse oneself with the true subject of the soul's life (what or whom it is about). We are no more than the stage or place where it happens, but where it happens for its own sake not for ours. The fact that it needs us to acquire a real presence in the world and undergo its process of further-determination must not go to our heads (Giegerich, 2012, p. 312).

Jungians, like Giegerich, often talk about the psyche or soul as if it in itself is a sentient being with a life of its own. This anthropomorphism is confusing at best. To fend off criticism, Jungians might say this is only a metaphorical or poetic way of speaking in aid of understanding. The question is why not speak plainly, focusing on the subject ("I") of psychological life, instead of introducing such quasi-mystical vocabulary? ${ }^{11}$

To be fair to Giegerich, he has usefully analysed contemporary issues such as globalisation (Giegerich 1996), but the tendency towards anthropomorphism ("globalisation" as autonomous being) is still his stumbling block. To eliminate ("dethrone") the individual from a description of (psychological) reality is Giegerich's attempt at revising the Jungian doctrine of individuation. But his colleague, Greg Mogenson, has judged this attempt a failure, arguing that the

10 See Giegerich (1996, 2004 or 2012) for a taste of his work. One devoted admirer, a Californian Jungian, Jennifer M. Sandoval, said at the beginning of a talk about Giegerich's work, "There's no doubt, people have trouble with Giegerich" (Sandoval, 2013) - because his writing is dense and difficult to follow! 11 Although Giegerich has said to Ann Casement that for him "there is no such thing as a soul. The soul does not exist. It is the depth of the logical life at work in what happens, no more" (Casement, 2011). This admission makes it more intriguing why he did not use less mystifying language in his writings.

Language and Psychoanalysis, 2018, 7 (1), 84-105. 
distinction between the individual and the collective remains vitally important (Mogenson, undated).

In a helpful paper on Giegerich's work, the London-based Jungian Ann Casement has published a quote from the personal communication she received from Giegerich regarding his way of working with patients:

In the consulting room I try to be present with such a psychologically-trained consciousness, but otherwise forget theories and approach the patient unprejudiced (as much as is humanly possible) in the spirit of Nowness and Eachness. The concentration is on this phenomenon now (this dream, symptom, memory, fantasy today). And the question is: what does it need? Here, I think my intuition needs to come into play. Great openness. No 'technique'. No psychological jargon (rarely do I use words like anima or shadow or self, etc. I avoid psychological brainwashing of my patients: staying with what shows itself!) Undogmatic. Improvisation, playing it by ear. This also requires honesty: my honest response at this moment to what shows itself. The work can be very different with different patients, but also different from session to session with one and the same patient. Openness to the Now (which even includes the Now of my mood and my perspective)... Especially important is for me the respect for the psychological difference. I try to be present in the sessions as the concrete ordinary person that I am (human, all-too-human) and to also see the ordinary human being in my patient. (Casement, 2011, pp. 539540)

I believe this way of working is the best (as one human being with another, not relying on techniques or jargons, but with a receptive and mentalising attitude) - the question is, why then does Giegerich theorise in such an opaque and mystifying way?

If an analyst does not think of the id, ego or soul as entities in the mind, she should desist from describing a patient's experience of emotional conflicts in terms of, e.g., "a cruel primitive superego watching the patient all the time", or "the superego masquerading as the ego causing the patient enormous pain". Even if she meant this metaphorically, the reader (and of course the patient) would be forgiven for thinking that she does believe the superego exists as an entity with a will and power of its own. If the analyst argues that her description is only a metaphorical way of talking, it would be incumbent on her to make sure that the patient (and readers of her writings) does understand this.

It is not my intention to suggest metaphors like "superego" should never be used. Psychotherapy would be poorer if that were the case. The use of metaphors leads to expansion of the horizon of possibilities. It moves one area of experience to another, 
one way of remembering to the next, forming a trajectory, an arc of meaning(s), thus enriching understanding. But there is always the risk of a metaphor becoming reified, or being fixed in its meaning by "experts" with power; and hence the paramount importance of finding a way of writing and talking about therapy (especially to patients) that does justice to the distinction between the denotative and the connotative use of language, and the nature of its fluidity.

\section{The Trap of Theories}

Many psychologists and psychotherapists are beguiled by the excitement of building theoretical models, particularly grand, overarching theories. They have the example of Freud to follow, whose theories have lasting impact on the evolution of psychotherapy. But theory often becomes a trap. This trap does not just affect psychoanalysis, but most other therapies as well. One example, from outside the psychoanalytic world, is the Self-Regulatory Executive Function Model (S-REF) formulated by the British clinical psychologist Adrian Wells ${ }^{12}$ to explain emotional disorders. Structures such as "control", "appraisal", "plans" etc are postulated as components of the cognitive architecture within a multi-level cognitive processing system that determines the emotions and behaviour of the individual. While it is often the case that such cognitive models contain scant reference to established neuroanatomical structures or neurophysiological pathways, it is implied that the model is based on the actual functioning of the brain.

With Freud as exemplar, analysts do not shy away from postulating various psychic structures in theory building, even though they might not employ sophisticatedlooking flow diagrams or elaborate acronyms as cognitive therapists often do. Many analysts talk about symptoms as the outward expression of deeper psychic structures, and therapy is to understand these structures as a route to removing the symptoms. ("Removing the symptoms" is a mechanistic medicine way of talking.) It is unclear whether any attention is paid to the distinction between causes and reasons in such theorising; or whether the theorists are aware of the possibility of committing category errors.

The allure of theory building may entice the psychotherapist into talking nonsense unawares. John Heaton warned about this pitfall forty years ago, in a book chapter that unfortunately is rarely referred to nowadays. Proper theoretical work in psychotherapy, he argues, is not about building complicated models of how structures in the mind (be they automatic negative schemas or unconscious defence mechanisms) cause neurosis. Rather it should be an endeavour to "foster the recognition of the limits of language and the contexts in which words come to represent", and to clarify "the nature of action"13 One example Heaton has used to illustrate the importance of explicating the workings of language is to ask how we would react if a woman said her husband "reported" to her that he had made an observation of his feeling of love towards her. No doubt we would think this odd -

12 This complicated sounding model that Wells has created is basically a cognitive therapy model. See Wells (2000).

13 Heaton (1979, p. 194).

Language and Psychoanalysis, 2018, 7 (1), 84-105.

http://dx.doi.org/10.7565/landp.v7i1.1584 
ordinarily the husband would simply tell his wife "I love you". There is nothing to report, so to speak; the declaration of love is not a matter of reporting.

In a similar vein, if, as therapists, we make patients "report" to us their thoughts and feelings or symptoms and complexes, we are removing them away from the natural situation of first and second person (I-and-you) interaction, and turning their experience into a thing that could be observed and reported on (it cannot be; experience is subjective).

Theoretical work in psychotherapy is not about producing notions such as Oedipus Complex and claiming empirical verifiable status for them. Such notions cannot be judged in terms of their truth or otherwise but only in terms of their usefulness in the hermeneutic task. Meaning is not the same as truth; psychotherapy is dealing with the former not the latter, especially not in its capitalised form.

"I am angry", "I love you" or "I feel hopeless" is a declaration, a telling, not a reporting of internal state which could be observed or content of the mind which could be inspected objectively. "Telling people things calls for a response or series of actions between the people concerned" 14 Even the utterance "my mother has died" is not a report but a telling that demands a response (say, from the therapist). Psychotherapy is not a theoretical science like physics but a practical science like politics or ethics. It inhabits the ordinary world, not the scientific world; its language is the vernacular, open-textured and equivocal, not definitions-bound and univocal; it cannot be couched in terms of the logical-deductive language of physics. Thus theory in psychotherapy cannot take the form of theories in physics or mechanistic medicine. Heaton suggests that "[s]ome procedures of psychotherapy could be seen as rituals designed to evoke the recognition of powers latent in the patient which are necessary to his being able to act in a satisfying way." ${ }^{2}$ Therefore, theoretical work in psychotherapy is to do with clarifying the language we use to help patients know themselves better through interacting with the therapist in relevant and meaningful ways, thereby getting in touch with their own resources which might enable them to live differently. To use an old-fashioned term, psychotherapy is a moral practice, rather than a scientific one.

Apart from bringing Wittgenstein's work to bear on psychotherapy (Heaton 2010), John Heaton has also written extensively about the importance of phenomenology and the ancient Greek philosophy of scepticism in helping us think about what psychotherapy is. ${ }^{16}$ Despite criticism of being obscure and impossible to grasp, phenomenology has undoubtedly made one major contribution to philosophy: the idea of the fundamental inseparability of subjectivity from the world. While we do not have to use the rather clunky phrase "being-in-the-world", it is important to acknowledge the interdependence between subject and world - neither can exist without the other. Things do not exist, in any meaningful way, in and of themselves. They are always in a relationship to the subject who acts on them.

\footnotetext{
${ }^{14}$ Heaton $(1979$, p. 180).

15 Heaton (1979, p. 187).

16 See, for example, Heaton (1993) and Heaton (1997).

Language and Psychoanalysis, 2018, 7 (1), 84-105. 
One central concept in phenomenology is intentionality - not in the sense of intention (as in motive), but "directedness". The experience of being alive is never an isolated "essence", but a relatedness, a connection (to be "directed" towards) of subjective action in and to a world which the subject inhabits. Thus intentionality is that which binds subject (person) and object (world) in an indivisible unity.

Heaton (1993) said "[p]sychotherapy depends on the cultural and traditional world in which the patient and therapist live and have their being. Conversation, the way we move people and are moved, the power of language, all depend on the cultural regularities and values embodied in our use of language" (p. 114). Thus people find themselves ("have their being") in the context of a world, and they construct a life in and through this world.

\section{Hermeneutics and the Search for Meaning}

If psychotherapy is a project through which we explore and grasp the meaning of existence ("have our being"), the question of context must be attended to. In this regard, social constructionism offers important insights similar to, though also different from, what phenomenology provides. ${ }^{17}$ The most significant feature of a social constructionist perspective is the prominence given to the collective construction of meanings, narratives, worldviews, discourses, etc within any community. The meaning of a handshake is only intelligible in the sort of modernwestern society like ours, but not in say certain African tribal communities. Within a western society, a particular handshake might only be meaningful to you if you are a member of, e.g., the Freemasons. By the same token, the meaning of being overweight is socially and culturally determined, and its construction is not the result of one single individual's passing whim, although the individual's psychology has a part to play. Even the notion of "self" cannot be taken for granted as a universal, unitary given, but as a socially constructed discourse which requires reflexive analysis in the context of specific socio-cultural and political circumstances.

The social constructionist notion of narrative is closely associated with story-telling, myth-making, and the idea of "there could be meaning in all this". A narrative must not be divorced from the social world from which it arises. To put experiences into a narrative is to enable meanings to emerge, to make possible the formation of a Gestalt, to create a world out of chaos, out of the void, almost as God did at the dawn of the universe, as the first chapter of the Book of Genesis so poetically describes. This is also poetically portrayed in Saint John's Gospel: "In the beginning there was the Word, and the Word was with God and God created the world through the Word..." We don't have to be a Christian to see beauty in the Genesis myth or in Saint John's description. We don't have to take this literally; we only need to think about it poetically, metaphorically - how the Word has made the world!

In psychotherapy, narratives can be constructed at different levels: the level of a single narrated event; the level of various stories coming together to yield richer meaning during a therapy session; the level of narratives constructed through a whole

${ }^{17}$ There is a large literature in social constructionism; a good starting point is John Shotter's work, e.g., Shotter (1993).

Language and Psychoanalysis, 2018, 7 (1), 84-105.

http://dx.doi.org/10.7565/landp.v7i1.1584 
therapy over months or years, moving towards a meaningful completion of therapy work; or indeed the level of the narrative of a lifetime, of our one and only existence, each and every one of us. ${ }^{18}$ Meaning and narrative are inseparable. From an existentialist point of view, the creation of narratives is our battle against meaninglessness (the chaos and void in the Genesis story). This is a noble task to which psychotherapy can hopefully contribute.

The hermeneutic turn in twentieth century philosophy has a great impact on the reimagining of psychoanalysis as a discipline of narrative-interpretative assimilation of the meaning-relationships between symbols and psychological life. Thus psychoanalysis cannot be judged according to criteria appropriate for the physical sciences which are dealing with objective observations and facts.

Jürgen Habermas and Paul Ricoeur believe that psychoanalysis has shown a selfmisunderstanding of itself as a natural science, and thus a hermeneutic revision is needed. But Aldolf Grünbaum (1984) is insistent that such revision is unacceptable. Grünbaum's critique of Habermas and Ricoeur is basically saying they have got it wrong because Freud did believe psychoanalysis was a natural science whose validity could be tested in objective ways. ${ }^{19}$ Grünbaum is missing the point: the revisionist aim of authors like Habermas and Ricoeur is precisely to re-interpret psychoanalysis in such a way as to draw out its real contribution to human knowledge, notwithstanding Freud's aligning psychoanalysis with the natural sciences. To Ricoeur, the criteria to judge the validity of psychoanalytic theory and therapy are: coherence, narrative intelligibility, interpretative consistency and usefulness to the patient (Ricoeur 1981). The value of psychoanalysis is in contributing to this hermeneutic turn, regardless of what Grünbaum said about Freud's intention.

\section{Cultivating Intuition and Ordinariness}

To borrow Winnicott's idea of "transitional object", ${ }^{20}$ it is possible to suggest that words serve as transitional objects (the "in-betweens") that bind the subject and the world together. While there are psychotherapists who use the idea of words as

${ }^{18}$ One interesting work which captures the construction of a lifetime narrative is the personal and reflective book that Patrick Casement (2006), a British psychoanalyst, has written, after his retirement, about his life and his experience of becoming a psychoanalyst. Although my view about psychoanalysis is different from his, I do admire his work.

${ }^{19}$ Grünbaum spends one third of his rambling 1984 text to critique hermeneutic approaches, particularly the work of Ricoeur and Habermas. He also rejects Karl Popper's claim that psychoanalysis does not meet the criterion of falsifiability. Grünbaum's aim in his book is to prove that Freud has failed to provide incontrovertible clinical facts for his theory, and it is on this basis he rejects psychoanalysis. For a critique of Grünbaum's critique, see Wollheim (1993, Chapter VI, pp. 91-111).

20 There is much reference to "transitional objects" in Winnicott's writings; see, for example, the first chapter in Winnicott (1971, pp. 1-25).

Language and Psychoanalysis, 2018, 7 (1), 84-105.

http://dx.doi.org/10.7565/landp.v7i1.1584 
transitional objects to refer to emotionally significant (childhood) words, ${ }^{21} \mathrm{I}$ am using it to suggest that words in general (language as a whole) constitute a "me-but-not-me" transitional bridge between subjectivity and the external world. As such, words occupy a border (the transitional space) crucial for the development of self-other relationships.

Whether we think in terms of the phenomenological connectedness between subject and world, or the socially constructed nature of experience, the mediational importance of language is indisputable. Therefore, careful analysis of how words are used and understood in ordinary life remains the most important task for philosophers as well as psychotherapists. It is a task that ensures the transitional space between subject and world is shaped in ways that nourish and protect, where life will be cultivated and will flourish.

The discerning reader will have noticed that this essay relies on a number of rather dated sources. Perhaps it can be argued that, as the old adage goes, "there is nothing new under the sun", and despite the proliferation of many fashionable "new" therapies, we might be falling into the trap of words which do not point to anything real if we are fascinated by every new therapy that comes along.

The appropriation of ordinary words and turning them into a new school of "therapy" is an oft-repeated phenomenon nowadays. "Acceptance" and "commitment" are part of our vernacular for a very long time, before they were requisitioned to christen a new therapy. Through either reification (turning words into mechanisms) or mystification ("mode deactivation therapy" sounds scientific), ambitious therapists set up therapy schools, patent their techniques and disseminate their specialist knowledge to those willing to pay.

The psychological therapy world is like a Tower of Babel, where gurus jostle for prime positions. Perhaps many therapists find it impossible to give up the alchemist's dream - turning base metal into gold - of creating glossy, enticing products with promises such as "I Can Make You Thin", "I Can Make you Happy", or "I Can Make You Confident"... There is a simple solution for every problem in life, just believe in the therapy guru!

What if suffering is the essence of human existence, without which we are perhaps not living fully? Should psychotherapists aspire to being alchemists of the mind, trying to turn the messiness of human life into the sunny upland of eternal bliss? In all this clamour, it would be immensely helpful to keep in mind an idea of Freud's (even if we do not adopt his theories) - that we can only hope, through psychotherapy, to turn neurotic misery into ordinary unhappiness.

This essay is not meant to be a definitive critique, nor a comprehensive review, of psychoanalysis, but a reflection on a number of questions that have preoccupied me for a long time. I do acknowledge the importance of Freud, and am aware of the many

21 In Favero \& Ross (2003), the authors use this idea to refer to emotionally significant, early childhood words (mother tongue), particularly when uttered in a therapy situation where therapy is conducted in a different language and where the therapist does not speak the patient's mother tongue.

Language and Psychoanalysis, 2018, 7 (1), 84-105.

http://dx.doi.org/10.7565/landp.v7i1.1584 
varied and stimulating readings of his work. But turning psychoanalysis (or psychotherapy) into a narrow-minded, exclusivist profession may not be for the best it should be "owned" by all who care to think and think deeply and honestly. Philosophers and novelists and artists might be more capable of understanding psychoanalysis and extending it beyond institutional confines than professional psychoanalysts. Their writings are often more helpful than those of Freud's (or Jung's) devoted acolytes.

The philosopher Jonathan Lear said, "[i]t is part of the logic of psychoanalysis and philosophy that they are forms of life committed to living openly - with truth, beauty, envy and hate, wonder, awe and dread" (Lear, 1998, p. 5). Living openly suggests an attitude that is reflexive in thinking and tentative in judging, which is epitomised by the work of the psychotherapist Peter Lomas who, although trained in psychoanalysis, was never dogmatic or partisan. In the Guardian obituary on Lomas dated 24 February 2010, David Ingleby was quoted as describing Lomas as offering "not answers, but questions; not dogmas, but doubts".

Although he acknowledged Freud's importance, Lomas (1981, 1994, 1999) did not shy away from criticising psychoanalysis. While Giegerich theorises in an inaccessible manner, his description of his way of working with patients in therapy (see above) is not too dissimilar to what Lomas would recommend. Perhaps many thoughtful psychoanalysts and psychotherapists do work like this clinically. Lomas has emphasised the limitation of techniques and the limitation of analytic interpretations; qualities such as ordinariness, openness, receptivity, intuition, authenticity and wisdom are much more vital to psychotherapy. To him, therapy is a moral practice, not in the sense of moralising or telling the patient what is right and wrong, but an attempt to work towards the fundamental human question of how to live life, or as Jonathan Lear $(2004,2014)$ has put it, how to live well. Lear talks about freedom as the "final cause" (teleological cause or goal) that psychoanalysis as a therapy should be working towards (Lear, 2009). Grappling with the issue of freedom is no doubt part of practising psychotherapy as a moral endeavour.

Lear (2014) has summarised what the best attitude towards Freud should be:

All of this suggests that if psychoanalysis is to live up to its promise of being a moral psychology — one which contributes as it comes to understand what it is to lead a full, rich, meaningful human life - it must find ways to mourn Freud's legacy, and move on. Even now, we are only at the beginning of such a process ( $\mathrm{p}$. 480).

\section{Author's Biographical Note}

Chin Li was formerly consultant clinical psychologist with Greater Glasgow \& Clyde Health Board in Scotland and psychology professional lead for Renfrewshire \& Inverclyde Sector. He retired from the NHS in 2015, and is now devoting his time to writing. 


\section{Acknowledgment}

I am grateful to the anonymous reviewer who has made suggestions that led me to exploring a number of writers and psychoanalysts I knew little about. I would also like to thank the Editor of this journal for her very helpful advice on the structure of the paper.

\section{References}

Bell, D. (2010). Psychiatry and psychoanalysis: a conceptual mapping. In A. Lemma \& M. Patrick (Eds.). Off the couch: Contemporary psychoanalytic applications (pp.176-193). London, UK: Routledge.

Buchanan, B. W. (2010). Oedipus against Freud: Myth and the end(s) of humanism in Twentieth-Century British literature. Toronto, Canada: University of Toronto Press.

Casement, A. (2004). Who owns psychoanalysis? London, UK: Karnac.

Casement, A. (2011). The interiorizing movement of logical life: reflections on Wolfgang Giegerich. Journal of Analytical Psychology, 56, 532-549.

Casement, P. (2006). Learning from life: Becoming a psychoanalyst. London, UK: Routledge.

Deleuze, G., \& Guattari, F. (1983 \{French original published in 1972; original English translation published in 1977\}) Anti-oedipus: Capitalism and schizophrenia. Minneapolis, MN: University of Minnesota Press.

Ellenberger, H. F. (1970). The discovery of the unconscious: The history and evolution of dynamic psychiatry. New York, NY: Basic Books

Favero, M., \& Ross, D. R. (2003). Words and transitional phenomena in psychotherapy. American Journal of Psychotherapy, 57, 287-299.

Fenichel, T. (2015). Uncanny belonging: Schelling, Freud and the vertigo of freedom. PhD Dissertation, Boston College Department of Philosophy.

Ffytche, M. (2011). The foundation of the unconscious: Schelling, Freud and the birth of the modern psyche. Cambridge, UK: Cambridge University Press.

Gellner, E. (1985). The psychoanalytic movement. London, UK: Granada.

Giegerich, W. (1996). Opposition of 'individual' and 'collective' - psychology's basic fault: reflections on today's Magnum Opus of the soul. Harvest: Journal for Jungian Studies, 42, 7-27.

Giegerich, W. (2004). The end of meaning and the birth of man. Retrieved from: www.cgjungpage.org/pdfdocuments/EndofMeaning.pdf

Giegerich, W. (2012). What is soul? New Orleans, LA: Springer.

Grünbaum, A. (1984). The foundations of psychoanalysis: A philosophical critique. Berkeley, CA: University of California Press.

Heaton, J. M. (1979). Theory in psychotherapy. In N. Bolton (Ed.), Philosophical problems in psychology (pp. 176-196). London, UK: Methuen.

Heaton, J. M. (1993). The sceptical tradition in psychotherapy. In L. Spurling (Ed.), From the words of my mouth: Tradition in psychotherapy. London, UK: Tavistock/Routledge.

Heaton, J. M. (1997). Pyrrhonian scepticism: A therapeutic phenomenology. The Journal of the British Society for Phenomenology, 28, 80-96.

Heaton, J. M. (2010). The talking cure: Wittgenstein on language as bewitchment and clarity. Basingstoke, UK: Palgrave Macmillan. 
Home, H. J. (1966). The concept of mind. International Journal of Psycho-Analysis, 47, 42-49.

Kaplan-Solms, K., \& Solms, M. (2000). Clinical studies in neuro-psychoanalysis. London, UK: Karnac.

Kircher, T., \& David, A. (2003). Self-consciousness: an integrative approach from philosophy, psychopathology and the neurosciences. In T. Kircher \& A. David (Eds.), The self in neuroscience and psychiatry (pp. 445-473). Cambridge, UK: Cambridge University Press.

Lear, J. (1998). Open minded: Working out the logic of the soul. Cambridge, MA: Harvard University Press.

Lear, J. (2004). Psychoanalysis and the idea of a moral psychology: memorial to Bernard Williams' philosophy. Inquiry, 47, 515-522.

Lear, J. (2005). Freud. Abbington, UK: Routledge.

Lear, J. (2009). Technique and final cause in psychoanalysis: four ways of looking at one moment. International Journal of Psychoanalysis, 90, 1299-1317.

Lear, J. (2014). Mourning and moral psychology. Psychoanalytic Psychology, 31, 470-481.

Lemma, A. (2003). Introduction to the practice of psychoanalytic psychotherapy. Chichester, UK: Wiley.

Levin, F. M. (2003). Mapping the mind: The intersection of psychoanalysis and neuroscience. London, UK: Karnac.

Lomas, P. (1981). The case for a personal psychotherapy. Oxford, UK: Oxford University Press.

Lomas, P. (1994). Cultivating intuition: An introduction to psychotherapy. London, UK: Penguin.

Lomas, P. (1999). Doing good? Psychotherapy out of its depth. Oxford, UK: Oxford University Press.

McGrath, S. J. (2011). Is Schelling's nature-philosophy Freudian? Analecta Hermeneutica, 3, 1-20.

Mogenson, G. (undated). Response to Wolfgang Giegerich's “Reflections on today's Magnum Opus of the soul". Retrieved from:

www.ispdi.org/images/stories/PDFdocuments/Reply_to_Giegerich.pdf

Oppenheim, L. (2005). A curious intimacy: Art and neuro-psychoanalysis. London, UK: Routledge.

Phillips, A. (2007). After Strachey. London Review of Books, 29, 36-38.

Phillips, A. (2014) Becoming Freud: the making of a psychoanalyst. New Haven, CT: Yale University Press.

Ricoeur, P. (1981). Hermeneutics and the human sciences (Edited and translated by J. B. T. Thompson). Cambridge, UK: Cambridge University Press.

Sandoval, J. M. (2013). The challenge of Giegerich. Talk given at C. G. Jung Institute of Los Angeles. Retrieved from:

www.jennifersandoval.com/Giegerich\%20for\%20Beginners.pdf

Sartre, J-P. (1974). Between existentialism and Marxism. London, UK: NLB.

Shotter, J. (1993). Conversational realities: Constructing life through language. London, UK: Sage.

Smail, D. (1987). Psychotherapy as subversion in a make-believe world. Changes: The Psychology and Psychotherapy Journal, 5, 398-402.

Solms, M. (2013). The conscious id. Neuropsychoanalysis, 15, 5-19

Solms, M., \& Turnbull, O. (2002). The brain and the inner world: An introduction to the neuroscience of subjective experience. London, UK: Karnac.

Language and Psychoanalysis, 2018, 7 (1), 84-105.

http://dx.doi.org/10.7565/landp.v7i1.1584 
Wells, A. (2000). Emotional disorders and metacognition: Innovative cognitive therapy. Chichester, UK: Wiley.

Winnicott, D. W. (1971). Playing and reality. London, UK: Tavistock.

Wittgenstein, L. (1958). Philosophical investigations. Oxford, UK: Blackwell.

Wollheim, R. (1993). The mind and its depths. Cambridge, MA: Harvard University Press. 